The yearly expenditure on ESR is 216.000 \$ USD in our hospital. Measuring ESR only for those suspected for an inflammatory state will reduce the expenditure for ESR measurement by $60 \%$ and save 129.600 \$ USD annually.

We conclude that elevated ESR, in most cases, can be explained by already known diagnosis or laboratory abnormalities and thus is ineffective and cost effective as screening tool for hospitalized patients in internal medicine wards.

\title{
Acknowledgement
}

We thank the nursing staff of Internal Medicine „B” ward and especially Rutty Ostrowizky, for their invaluable help in this project.

\section{VALOAREA VITEZEI DE SEDIMENTARE A HEMATIILOR CA ŞI TEST SCREENING LA PACIENT,II SPITALIZATII}

\section{Rezumat}

Introducere în temă: Viteza de sedimentare a hematiilor (VSH) a fost introdusă în practică cu mai mult de 80 de ani în urmă, fiind utilizată pe scară largă ca un test simplu al activității inflamatorii. Am evaluat eficiența și raportul cost eficiență al VSH pentru screening-ul pacienților spitalizați.

Pacienți și metode: Datele au fost obținute de la pacienții internați la Spitalul Hasharon, secția de Medicină Internă B, pe o perioadă de două luni. Pacienții consultați ambulator la Cabinetul de Medicina Familiei Nahalat-Zvi, Servicii Medicale Clalit, Israel, pentru suspiciunea de boli inflamatorii, au servit ca și grup control. Pe lângă VSH, alte date colectate au fost: sexul, vârsta, diagnosticul, medicația și date de laborator.

Rezultate: Valorile VSH au fost disponibile pentru 218 pacienți spitalizați și pentru 21 de pacienți consultați în ambulator. Pacienții spitalizați au avut vârsta semnificativ mai înaintată decât grupul control $(70,9+15,5$ vs. $60,4+14,8, p=0,003)$, un hematocrit mai scăzut $(H c t)(37,4+5,6$ vs. $41,4+3,9, \mathrm{p}=0,003)$ și un VSH mai mare $(49,8+30,2$ vs. $31,6+20,1, \mathrm{p}=0,007)$ decât pacienții din ambulator. Printre pacienții spitalizați, au fost determinate valori crescute ale VSH $(>70 \mathrm{~mm} / \mathrm{h})$ în $30.6 \%$ din cazuri, în corelație cu vârsta $\geq 75(\mathrm{p}=0,04)$, sexul feminin $(\mathrm{p}=0,01), \mathrm{Hgb}<12 \mathrm{~g} / \mathrm{dl}$ $(\mathrm{p}<0,0001)$, leucocitele $>13.000 / \mathrm{micl}(\mathrm{p}=0,03)$, trombociții $</=100.000 / \mathrm{micl} \mathrm{sau} \geq 400.000 / \mathrm{micl}$ $(\mathrm{p}=0,0001)$, albuminele $<3,3 \mathrm{~g} / \mathrm{dl}(\mathrm{p}<0,0001)$ și globulinele $<3,3(\mathrm{p}<0,0001)$.

Concluzii: VSH este ineficientă ca și test screening la pacienții spitalizați, chir și pentru vârstnici. Măsurarea VSH doar pentru cazurile suspectate ca având status inflamator reduce semnificativ cheltuielile.

Cuvinte cheie: Viteza de sedimentare a hematiilor, test screening.

\section{Introducere}

Viteza de sedimentare a eritrocitelor a fost descrisă prima dată de către Fahraeus [1] în 1921, de atunci fiind utilizată pentru depistarea și monitorizarea diferitelor afecțiuni. Comitetul consultativ al Asociației Medicale din Columbia Britanică a elaborat un ghid clinic privitor la VSH, cu recomandările de a fi utilizat în caz de suspiciune de boli inflamatorii, neoplazice sau infecțioase, sau când nu se ajunge la diagnosticul specific prin alte mijloace; testul nu se recomandă la pacienții asimptomatici și nici în cazul investigațiilor de rutină. Deși testul în sine nu este scump, el este utilizat frecvent, astfel costurile se cumulează. 
De mai mult de 30 de ani, ghidurile locale aplicate în departamentul de medicină internă „B” al spitalului Hasharon, includ o verificare de rutină a hemoleucogramei, alte probe de laborator și VSH pentru fiecare pacient în primele 24 ore de la internare.

Acest studiu a fost elaborat pentru a evalua eficiența și raportul cost eficiență al VSH ca și instrument de screening al pacienților din secția de medicină internă.

\section{Materiale şi metode}

Au fost colectate date de la pacienții internați consecutive pe o secție de medicină internă, precum și de la pacienții consultați ambulator pentru afecțiuni inflamatorii într-un cabinet de medicina familiei, pe parcursul a două luni. Datele au incus: sexul, vârsta, diagnosticul acut și cronic și medicația. Datele de laborator au inclus: valorile VSH, hemoglobinei ( $\mathrm{Hgb})$, hematocritului (Hct), trombociților (Plt), leucocitelor (WBC), albuminelor (Alb) și globulinelor (Glob).

Diagnosticele pacienților au fost analizate și agregate în patru grupe: infecțioase (pneumonia, pielonefrita septică, etc.), inflamatorii (artrita, vasculite, boli de colagen, vasculare, etc), malignități (solide și hematologice) și altele. Primele trei grupe au inclus diagnostice în care erau de așteptat valori crescute ale VSH, iar ultima grupă cuprinde alte diagnostice, în care VSH crescut nu era de prevăzut.

\section{Analiza statistică}

Analiza statistică a fost efectuată utilizând softul Microsoft Excel, testele statistice fiind: $\mathrm{Chi}^{2}$ și testul-T cu două probe cu variații presupus egale. Probabilitatea a fost estimată prin indicele de confidență, în care o valoare $\mathrm{p}<0,05$ a fost considerată semnificativă.

\section{Rezultate}

Datele au fost colectate de la 270 pacienți consecutivi, valorile VSH fiind disponibile la 218 dintre ei $(81 \%)$ și la 21 de pacienți ambulatori.

Vârsta pacienților a fost cuprinsă între 18 și 98 (mediana 70,9 + 15,5), 53,4\% fiind femei (Tabel I). Valorile VSH au fost cuprinse între 4 și $130 \mathrm{~mm} / \mathrm{h}$ (mediana 49,8 + 30,2).

Valorile VSH au fost grupate în scăzute $(0-39 \mathrm{~mm} / \mathrm{h})$, medii $(40-69 \mathrm{~mm} / \mathrm{h})$ și crescute $(\geq 70$ $\mathrm{mm} / \mathrm{h})$. Niveluri scăzute, medii sau crescute au fost găsite la $97(44,3 \%), 55(25,1 \%)$ și respectiv 67 (30,6\%) pacienți.

Creșterea VSH a fost asociată cu vârsta avansată, sexul feminin, anemia, leucocitoza, trombocitoza și trombocitopenia, hipoalbuminemia și hipoglobulinemia (Tabel II).

Asocierea dintre creșterea VSH și sexul feminine a fost accentuată când datele au fost corelate cu sexul și vârsta. Componenta determinantă a fost Htc, care a fost semnificativ mai scăzut la femei comparativ cu bărbații, și la vârstnici comparativ cu tinerii (Tabel III).

Analiza prevalenței în funcție de medicația comună utilizată a fost efectuată între pacienții cu VSH crescut $(\geq 70 \mathrm{~mm} / \mathrm{h})$ și VSH normal. $\mathrm{Nu}$ a fost determinată o asociere între nivelul VSH și utilizarea aspirinei, corticosteroizilor, betablocantelor, blocanților de canale de calciu, inhibitorii enzimei de conversie ai angiotensinei (ACE-I), a blocanților receptorilor de angiotensină (ARB), a inhibitorilor de pompă protonică, statinelor, derivaților de sulfoniluree sau metformin.

Pacienții au fost grupați pe diagnostice infecțioase, inflamatorii, maligne și altele, măsurându-se VSH pentru fiecare grupă: 77,6 + 22,8, 69,3 + 33,4, 52,3 + 25 and 35,8 + 23,1, fiind semnificativ mai mare în infecții, inflamații și malignități vs. altele $(\mathrm{p}=0,008, \mathrm{p}<0,0001$ și respectiv $\mathrm{p}<0,0001)$.

Diagnosticele asociate cu valori crescute ale VSH (infecțioase, inflamatorii, sau maligne) au fost găsite în 13,4\%, 38,27\% și 78,8\% din grupurile cu VSH scăzut, mediu și crescut ( $<$ < 0,0001, Chi²). Totuși, deși 56,1\% din pacienții cu diagnostice infecțioase au avut valori crescute ale VSH, doar $15,2 \%$ din cei cu boli inflamatorii și 7,6\% din cei cu boli maligne, au avut valori crescute ale VSH (Figura 1). Patrusprezece pacienți $(6,4 \%)$ cu VSH mai mare de 70 nu au avut un diagnostic care să fie 
asociat cu creșteri ale VSH; dintre aceștia 12 aveau peste 85 de ani, cu anemie, hipoalbuminemie sau hiperglobulinemie.

Credibilitatea măsurării VSH a fost demonstrată la 18 pacienți (8.3\%), mai multe determinări fiind repetate pe parcursul internării, diferența medie între determinări a fost de $18 \mathrm{~mm} / \mathrm{h}$, doar $22 \%$ din acești pacienți având diferențe între măsurători de peste $22 \mathrm{~mm} / \mathrm{h}$.

Prin compararea spitalizați vs. ambulatori, pacienții spitalizați au fost semnificativ mai în vârstă decât grupul de control $(70,9+15,5$ vs. $60,4+14,8, p=0,003)$, au avut un hematocrit mai scăzut $(37,4+5,6$ vs. $41,4+3,9, \mathrm{p}=0,003)$ și un VSH mai mare $(49,8+30,2$ vs. $31,6+20,1, \mathrm{p}=0,007)$. Dintre pacienții consultați ambulator, doar unul (o femeie de 71 de ani) a avut VSH>70mm/h (5\%), pacienta fiind cunoscută cu valori ale VSH crescute de ani de zile, valori a căror cauză a fost căutată fără succes.

Costul unei determinări a VSH este de 18 \$ USD. Rata anuală de internări pe secția de medicină internă a spitalului nostru este de 12.000 pacienți/an, astfel costurile anuale pentru determinarea VSH se ridică la cca. 216.000 \$ USD (Tabel IV).

\section{Discuții}

Măsurarea VSH este o cale simplă și rapidă de evaluare a inflamației, fiind utilizată pe scară largă atât în ambulator cât și în spital. Pe departamentul nostru de medicină internă, VSH este utilizată ca și parte a investigațiilor de rutină efectuate fiecărui pacient internat, pe lângă hemoleucogramă, alte investigații sangvine și urinare. Scopul acestei lucrări este de a evalua aportul adus de măsurarea VSH în screening-ul pacienților spitalizați pe departamentul de medicină internă.

Am arătat că valorile crescute ale VSH sunt mai frecvente la pacienții spitalizați (23.8\%) decât la cei consultați în ambulator (5\%). Date similare publicate de Fincher și Page, reflectă severitatea relativă a afecțiunilor pacienților spitalizați [2].

Am determinat că există o asociere între nivelurile crecute ale VSH şi vârsta înaintată, sexul feminin, anemie, hipoalbuminemie și hipoglobulinemie, așa cum a fost relatat și de alți autori $[3,4]$. Smith și Samadian [3] au propus ideea că nivelul crescut al VSH la vârstnici, măsurat la populația sănătoasă, este determinat de inciddența crescută a bolilor oculte sau cunoscute la acest grup. De altfel, am arătat că la populația relativ omogenă a pacienților spitalizați, toți cunoscuți ca având o afecțiune, VSH este semnificativ mai mare la vârstnici, chiar și după ajustarea în funcție de sex, acest lucru fiind în parte datorat diferențelor în ceea ce privește hematocritul între grupele de vârstă. Creșterea VSH nu este un semn precoce al bolii maligne, de aceea, chiar și la grupul cu suspiciune de malignitate fără alte dovezi, nu este justificat screeningul prin VSH [5].

Acest studiu ridică întrebarea asupra eficacităţii și raportului cost-eficacitate al screeningului VSH la pacienții spitalizați și la populația generală, întrucât mai puțin de 1 din 10.000 de pacienți vor avea un beneficiu prin acest proces [6]. Prezumpția noastră de bază a fost că la pacienții deja spitalizați beneficiul adus de screeningul VSH va fi mai mare. Totuși, dintre pacienții spitalizați foarte puțini (2) au avut valori crescute ale VSH ca și semn izolat, fără alte semne de boală sau rezultate de laborator modificate.

Cheltuielile anuale pentru VSH în spitalul nostru se ridică la 216.000 \$ USD. Măsurarea VSH doar pentru cei suspicionați ca având status inflamator ar putea reduce cheltuielile pentru VSH cu $60 \%$, economisind 129.600 \$ USD anual.

În concluzie, creșterea VSH în majoritatea cazurilor poate fi explicată prin diagnosticul deja cunoscut sau prin modificările de laborator, ceea ce duce la ineficiență și creșterea nejustificată a cheltuielilor pentru folosirea ca instrument de screening al VSH pentru pacienții internați pe secțiile de medicină internă. 


\section{Mulțumiri}

Mulțumim echipei de asistente a secției de Medicină Internă „B” și în special lui Rutty Ostrowizky, pentru ajutorul neprețuit în acest proiect.

\section{References}

1. Fahraeus R. The suspension-stability of the blood. Acta Med Scand. 1921;55:1-228.

2. Fincher RM, Page MI. Clinical significance of extreme elevation of the erythrocyte sedimentation rate. Arch Intern Med. 1986;146(8):1581-3.

3. Smith EM, Samadian S. Use of the erythrocyte sedimentation rate in the elderly. Br J Hosp Med. 1994;51(8):394-7.

4. Sox HC Jr, Liang MH. The erythrocyte sedimentation rate. Guidelines for rational use. Ann Intern Med. 1986;104(4):515-23.

5. Mönig H, Marquardt $\mathrm{D}$, Arendt $\mathrm{T}$, Kloehn $\mathrm{S}$. Limited value of elevated erythrocyte sedimentation rate as an indicator of malignancy. Fam Pract. 2002;19(5):436-8.

6. Gronlie M, Hjortdahl $\mathrm{P}$. The erythrocyte sedimentation rate; its use and usefulness in primary health care. Scand J Prim Health Care. 1991;9(2):97-102.

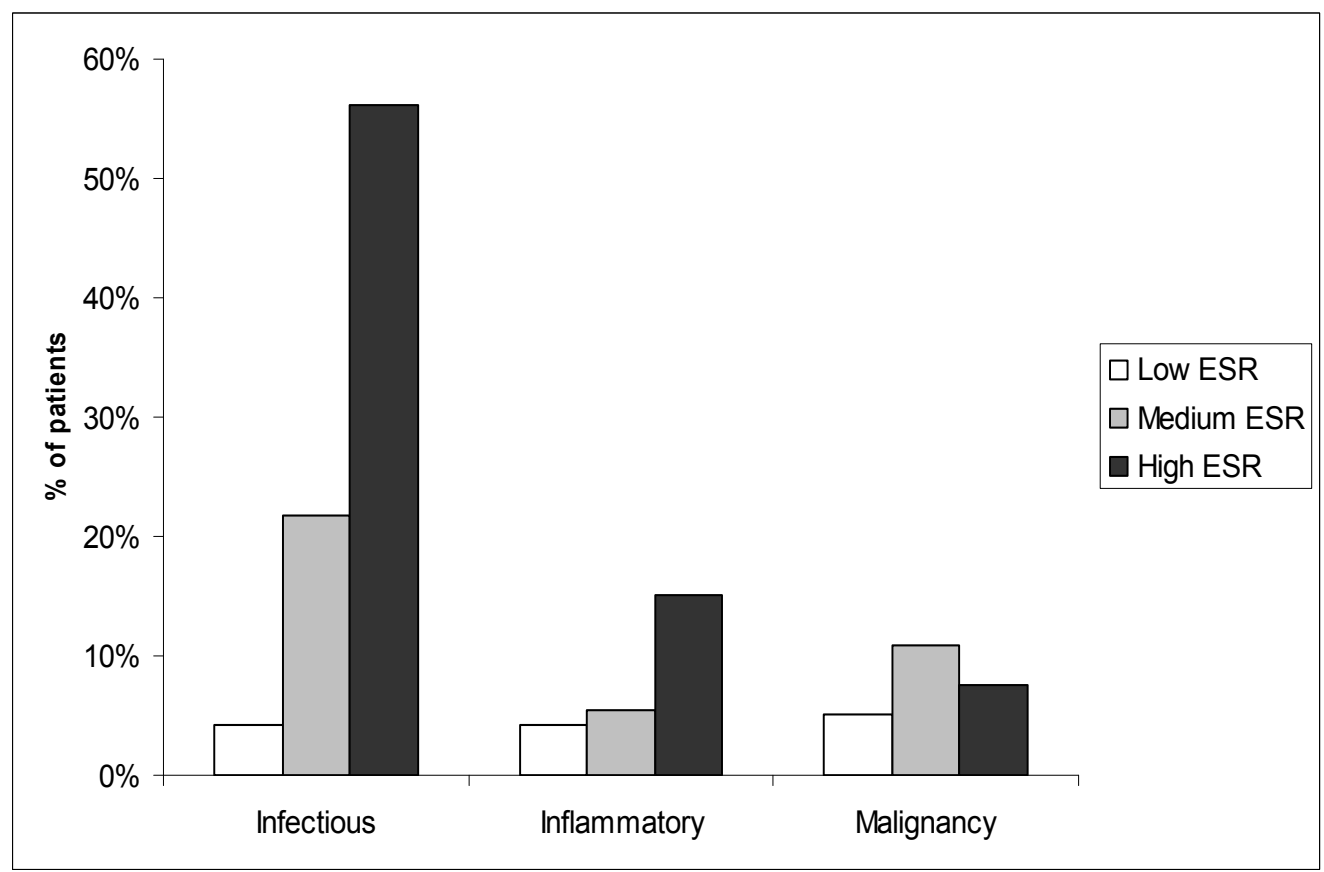

Figure (figura) 1: Distribution of erythrocyte sedimentation rate levels (low 0-39, medium 40-69 and high $\geq 70$ ) among patients with diagnosis compatible with elevated ESR (i.e. infectious, inflammatory and malignancy). Distribuția nivelurilor vitezei de sedimentare a eritrocitelor (scăzută 0-39, medie 40-69 şi ridicată $\geq 70$ ) la pacienții cu diagnostic compatibil cu niveluri ridicate ale VSH (de exemplu infecții, inflamații, malignități). 
Table (Tabel) I. Characteristics of 218 hospitalized patients (Caracteristicile celor 218 pacienţi spitalizați)

\begin{tabular}{lc}
\hline Parameter/Parametru & Evaluation/Evaluare \\
\hline Gender/Sex (Male/Female, Masculin/Feminin) Number/Număr & $101 / 117$ \\
Age/Vârsta (years/ani) & $70.9 \pm 15.5$ \\
Hgb (g/dl) & $12.5 \pm 3.4$ \\
Hct (\%) & $37.4 \pm 5.6$ \\
WBC/Leucocite (/micl) & $8.902 \pm 4.489$ \\
PLT/Trombociți (k/micl) & $252.6 \pm 95.3$ \\
Alb (g/dl) & $3.5 \pm 0.6$ \\
Glob (g/dl) & $3.0 \pm 0.6$ \\
\hline
\end{tabular}

Table (Tabel) II. Association between erythrocyte sedimentation rate and age, gender and laboratory values in 218 hospitalized patients (Asocierea dintre viteza de sedimentare a eritrocitelor şi vârstă, sex, valori de laborator, la 218 pacienți spitalizați)

\begin{tabular}{lcccc}
\hline \multirow{2}{*}{ Parameter/Parametru } & $\begin{array}{c}\text { No of patients/ } \\
\text { Nr. pacienților }\end{array}$ & ESR Average/VSH mediu & $\mathrm{p}$ \\
\hline Gender (sex) & Male (masculin) & 101 & $44.3 \pm 30.1$ & 0.01 \\
& Female (feminin) & 117 & $54.3 \pm 29.6$ & \\
Age (vârsta) (years/ani) & $<75$ & 115 & $45.7 \pm 30.6$ & 0.04 \\
& $\geq 75$ & 103 & $54.3 \pm 29.2$ & \\
Hgb (g/dl) & $<12$ & 99 & $63.4 \pm 30.0$ & $<0.0001$ \\
& $\geq 12$ & 119 & $38.5 \pm 25.3$ & \\
Hct (\%) & $<37$ & 94 & $64.0 \pm 94.0$ & $<0.0001$ \\
& $\geq 37$ & 124 & $39.1 \pm 124.0$ & \\
WBC (/micl) & $<13.000$ & 26 & $61.5 \pm 33.4$ & 0.03 \\
& $\geq 13.000$ & 192 & $48.2 \pm 29.5$ & \\
PLT (k/micl) & $>100,<400$ & 198 & $47.3 \pm 28.7$ & 0.0001 \\
& $\leq 100, \geq 400$ & 20 & $74.4 \pm 34.3$ & \\
Alb (g/dl) & $<3.3$ & 63 & $64.0 \pm 32.5$ & $<0.0001$ \\
& $\geq 3.3$ & 155 & $44.0 \pm 27.2$ & \\
Glob (g/dl) & $<3.3$ & 153 & $44.1 \pm 29.5$ & $<0.0001$ \\
& $\geq 3.3$ & 65 & $63.2 \pm 27.5$ & \\
\hline
\end{tabular}


Table (Tabel) III. Erythrocyte sedimentation rate and hematocrit analysis in correlation with gender and age (adjustment) 218 hospitalized patients (Analiza vitezei de sedimentare şi hematocritului în corelație cu sexul şi vârsta-ajustare- la 218 pacienți spitalizați)

\begin{tabular}{lcccc}
\hline Parameter/Parametru & \multicolumn{2}{c}{ ESR/VSH } & \multicolumn{2}{c}{ Hematocrit } \\
\cline { 2 - 5 } & $\begin{array}{c}\text { Average } \\
\text { (mediana) }\end{array}$ & $\mathrm{p}$ & $\begin{array}{c}\text { Average } \\
\text { (mediana) }\end{array}$ & $\mathrm{p}$ \\
\hline Gender (sex) & & & & \\
$\quad$ Male (masculin) & $45.6 \pm 27.6$ & 0.014 & $38.7 \pm 5.3$ & $<0.0001$ \\
Female (feminin) & $54.4 \pm 28.9$ & & $36.0 \pm 5.1$ & \\
Age (vârsta) & & & & \\
$\quad<75$ & $45.9 \pm 29.7$ & 0.021 & $38.2 \pm 5.7$ & $<0.01$ \\
$\geq 75$ & $54.3 \pm 26.9$ & & $36.5 \pm 4.7$ & \\
\hline
\end{tabular}

ESR/VSH = Erythrocyte sedimentation rate/Viteza de sedimentare a eritrocitelor

Table (Tabel) IV. Estimated annual cost of Erythrocyte sedimentation rate (in \$ USD) (Costul anual estimat al determinării VSH în \$ USD)

\begin{tabular}{lcc}
\hline & $\begin{array}{c}\text { Number of patients/Numărul } \\
\text { pacienților }\end{array}$ & ESR Cost (in \$ USD)/ costul \\
& 12.000 & 216.000 \\
\hline Screening & 4.800 & 86.400 \\
Targeted (Țintit) & & 129.600 Saved (economisiți) \\
\hline
\end{tabular}

\section{Traducere: dr. Bumbuluț Călin}

